National Marine

Fisheries Service

NOAA
Fishery Bulletin

कs established in 1881 \%
Spencer F. Baird

First U.S. Commissioner of Fisheries and founder of Fishery Bulletin
Abstract-The effects of barotrauma and other capture-related factors on the discard mortality of black sea bass (Centropristis striata) are poorly understood. The objective of this study was to estimate the discard mortality rate for black sea bass in the winter deepwater recreational fishery off New Jersey and to evaluate if swim bladder venting can reduce discard mortality. A total of 1823 fish were sampled at multiple depths (45, 58, and $67 \mathrm{~m}$ ) from November 2016 through March 2017. To estimate discard mortality at a depth of $45 \mathrm{~m}, 96$ individuals were tagged with acoustic transmitters and monitored with acoustic receivers. The majority (95\%) of fish captured across all depths exhibited effects of barotrauma, which were more prevalent at greater depths. Results from longitudinal survival analyses indicate that venting was the most significant predictor of mortality at a depth of $45 \mathrm{~m}$, with the estimated mean discard mortality rate being lower for vented $(20 \%)$ than non-vented $(49 \%)$ fish. Fight time had the largest statistical influence on the mortality of nonvented fish, whereas longer fight times $(>54 \mathrm{~s}$ ) resulted in higher mortality at a depth of $45 \mathrm{~m}$. Discard mortality may have been higher at greater depths, but venting and other recommended practices can mitigate mortality at all depths sampled.

Manuscript submitted 11 July 2019. Manuscript accepted 26 March 2020. Fish. Bull. 118:105-119 (2020). Online publication date: 1 May 2020. doi: 10.7755/FB.118.2.1

The views and opinions expressed or implied in this article are those of the author (or authors) and do not necessarily reflect the position of the National Marine Fisheries Service, NOAA.

\title{
Discard mortality of black sea bass (Centropristis striata) in a deepwater recreational fishery off New Jersey: role of swim bladder venting in reducing mortality
}

\author{
Douglas R. Zemeckis (contact author) ${ }^{1}$ \\ Jeff Kneebone ${ }^{2}$ \\ Connor W. Capizzano ${ }^{2,3}$ \\ Eleanor A. Bochenek ${ }^{4}$ \\ William S. Hoffman 5 \\ Thomas M. Grothues ${ }^{4}$ \\ John W. Mandelman ${ }^{2}$ \\ Olaf P. Jensen ${ }^{4}$
}

Email address for contact author: zemeckis@njaes.rutgers.edu

${ }^{1}$ Department of Agriculture and Natural Resources New Jersey Agricultural Experiment Station

Rutgers University

1623 Whitesville Road

Toms River, New Jersey 08755

${ }^{2}$ Anderson Cabot Center for Ocean Life New England Aquarium

1 Central Wharf

Boston, Massachusetts 02110

${ }^{3}$ School for the Environment

University of Massachusetts Boston

100 William T. Morrissey Boulevard

Boston, Massachusetts 02125

\author{
${ }^{4}$ Department of Marine and Coastal Sciences \\ Rutgers University \\ 71 Dudley Road \\ New Brunswick, New Jersey 08901 \\ ${ }^{5}$ Annisquam River Marine Fisheries Research \\ Field Station \\ Massachusetts Division of Marine Fisheries \\ 30 Emerson Avenue \\ Gloucester, Massachusetts 01930
}

Black sea bass (Centropristis striata) support valuable commercial and recreational fisheries in the United States along the East Coast and in the Gulf of Mexico (NMFS, 2018). In the northern stock area (i.e., Cape Hatteras, North Carolina, to Canada), the recreational fishery is frequently responsible for a significant proportion of the total catch (e.g., 61\% of the total 2015 catch; NEFSC, 2017) over a wide range of environmental conditions, habitats, and depths. These diverse recreational fisheries for black sea bass are governed by a suite of regulatory measures (e.g., minimum size limits, daily retention limits, and seasonal closures) in both state and federal waters along the East Coast of the United States (ASMFC ${ }^{1}$ ).

\footnotetext{
${ }^{1}$ ASMFC (Atlantic States Marine Fisheries Commission). 2017. 2017 Review of the
}

The discard rate of black sea bass in U.S. recreational fisheries is frequently high, with $33-56 \%$ of all captured fish being discarded annually from 2010 through 2015 (NEFSC, 2017). Discard rates vary by state and region in response to regulatory measures, "high-grading" practices, or angler catch-and-release conservation ethics. The latest stock assessments and fishery management plans for black sea bass assume a $15 \%$ discard mortality rate for the coast-wide, yearround recreational fishery (NEFSC, 2017). However, published estimates of the discard mortality rate for this

Atlantic States Marine Fisheries Commission fishery management plan for the 2016 black sea bass fishery; black sea bass (Centropristis striata), 12 p. ASMFC, Arlington, VA. [Available from website.] 
species vary considerably by region and depth of capture (e.g., 4.7-39.0\%), with an increase in discard mortality evident at greater capture depths (Bugley and Shepherd, 1991; Collins et al., 1999; Rudershausen et al., 2014).

As a physoclistous fish species, black sea bass often suffer from barotrauma when captured in deepwater $(>35 \mathrm{~m})$ recreational fisheries (Collins et al., 1999; Davis, 2002). Typical barotrauma effects experienced by physoclists are species-specific (Jarvis and Lowe, 2008; Hannah et al., 2014) but can include swim bladder expansion or rupture, exopthalmia, and stomach eversion (i.e., prolapse). Previous studies have demonstrated that even minor barotrauma can impair postrelease behavior, reduce submergence success, and result in high rates of discard mortality in many popular recreational species (e.g., Sauls, 2014; Curtis et al., 2015), including in black sea bass (Collins et al., 1999; Rudershausen et al., 2014). Fortunately, a growing body of evidence indicates that discard mortality can often be reduced by implementing barotrauma relief measures, such as swim bladder venting, or by using descending (i.e., release) devices to release fish at depth as opposed to at the sea surface (Drumhiller et al., 2014; Pulver, 2017; Runde and Buckel, 2018). Although the efficacy of venting and descending devices in mitigating mortality is fisheryand species-specific (Wilde, 2009; Curtis et al., 2015; Eberts et al., 2018), some evidence indicates that swim bladder venting is preferred and more likely to be practiced by recreational anglers because of its low cost and rapid application (Crandall et al., 2018).

Most of the recreational catch $(75 \%)$ and discards $(82 \%)$ in the northern stock of black sea bass were estimated to have occurred within state waters (i.e., $<5.6 \mathrm{~km}$, or 3 nautical miles, from shore) from spring through early fall during 2011-2015 (NEFSC, 2017). Popular recreational fisheries in the northeastern United States also target or catch black sea bass as bycatch in federal waters from the late fall through early spring. These fisheries predominantly occur at greater depths $(>35 \mathrm{~m})$, while black sea bass are carrying out their winter inshore-offshore seasonal migration (Moser and Shepherd, 2009). Although these deepwater fisheries account for a relatively small and uncertain proportion of total recreational catch of black sea bass (NEFSC, 2017), they provide valuable fishing opportunities for recreational fishermen during a season when relatively few species are available to target off the northeastern United States. Anecdotal reports suggest that many black sea bass captured in these deepwater fisheries experience moderate to severe barotrauma, but barotrauma relief measures (e.g., swim bladder venting) are neither required nor commonly practiced voluntarily. Furthermore, the extent to which environmental (e.g., cold water and air temperatures) and ecosystem (e.g., predator species and abundance) conditions influence black sea bass discard mortality during the winter in recreational fisheries off New Jersey is unknown.

Results of recent studies indicate that discard mortality rates in recreational fisheries are influenced by numerous biological, environmental, and technical factors (e.g., Capizzano et al., 2016, 2019; Weltersbach et al., 2019).
Therefore, fishery- or region-specific estimates of discard mortality and recommendations for anglers for best practices in catch and release of black sea bass are required to provide the information needed for stock assessments, fishery management, and conservation efforts. The objective of this study was to estimate the discard mortality rate for black sea bass captured in the winter deepwater recreational fishery off New Jersey and to evaluate if swim bladder venting can reduce discard mortality.

\section{Materials and methods}

\section{Study sites}

Black sea bass were sampled at 3 deepwater sites off the coast of southern New Jersey from December 2016 through March 2017 (Fig. 1A). The primary study site was a shipwreck (site A) located $\sim 85 \mathrm{~km}$ southeast of Sea Isle City, New Jersey, at a depth of $45 \mathrm{~m}$ and sampled from December 2016 through February 2017. At this location, consistently high rates of catch of black sea bass are produced at a depth range that is representative of common offshore fishing grounds for this species. To investigate how the condition of captured fish and discard mortality might vary by capture depth, sampling was conducted during February and March 2017 at 2 additional sites where the depths were $58 \mathrm{~m}$ (site B) and $67 \mathrm{~m}$ (site C), respectively.

\section{Sampling}

Prior to any sampling, an online survey of recreational black sea bass anglers and captains of vessels in this fishery was conducted during October and November 2016 to determine the reel type (e.g., conventional, spinning, or electric), tackle (e.g., line type and strength and hook type and size), and rigging techniques (e.g., leader material, length, and configuration) most commonly used in the winter recreational offshore fishery for black sea bass off New Jersey. This survey was primarily distributed through online message boards for recreational anglers. On the basis of results of this survey (number of respondents: 282), we chose standardized terminal tackle rigs for use on all tagging trips. These rigs consisted of a high-low rig (i.e., lead sinker at the bottom with 2 hooks attached above through dropper loops) made with 22.7-kg monofilament leader material and two 5/0-size octopus hooks (model 92553-BN, O. Mustad and Son ${ }^{2}$, Gjøvik, Norway). The volunteer anglers were allowed to use their own rods and reels to represent the variety used by anglers under typical conditions. The retrieve (i.e., gear) ratios of all reels were recorded, ranged from 2.5:1.0 to 7.1:1.0, and were classified broadly as low speed (reel retrieve ratio <5.0:1.0) or high speed (reel retrieve ratio >5.0:1.0).

\footnotetext{
${ }^{2}$ Mention of trade names or commercial companies is for identification purposes only and does not imply endorsement by the National Marine Fisheries Service, NOAA.
} 


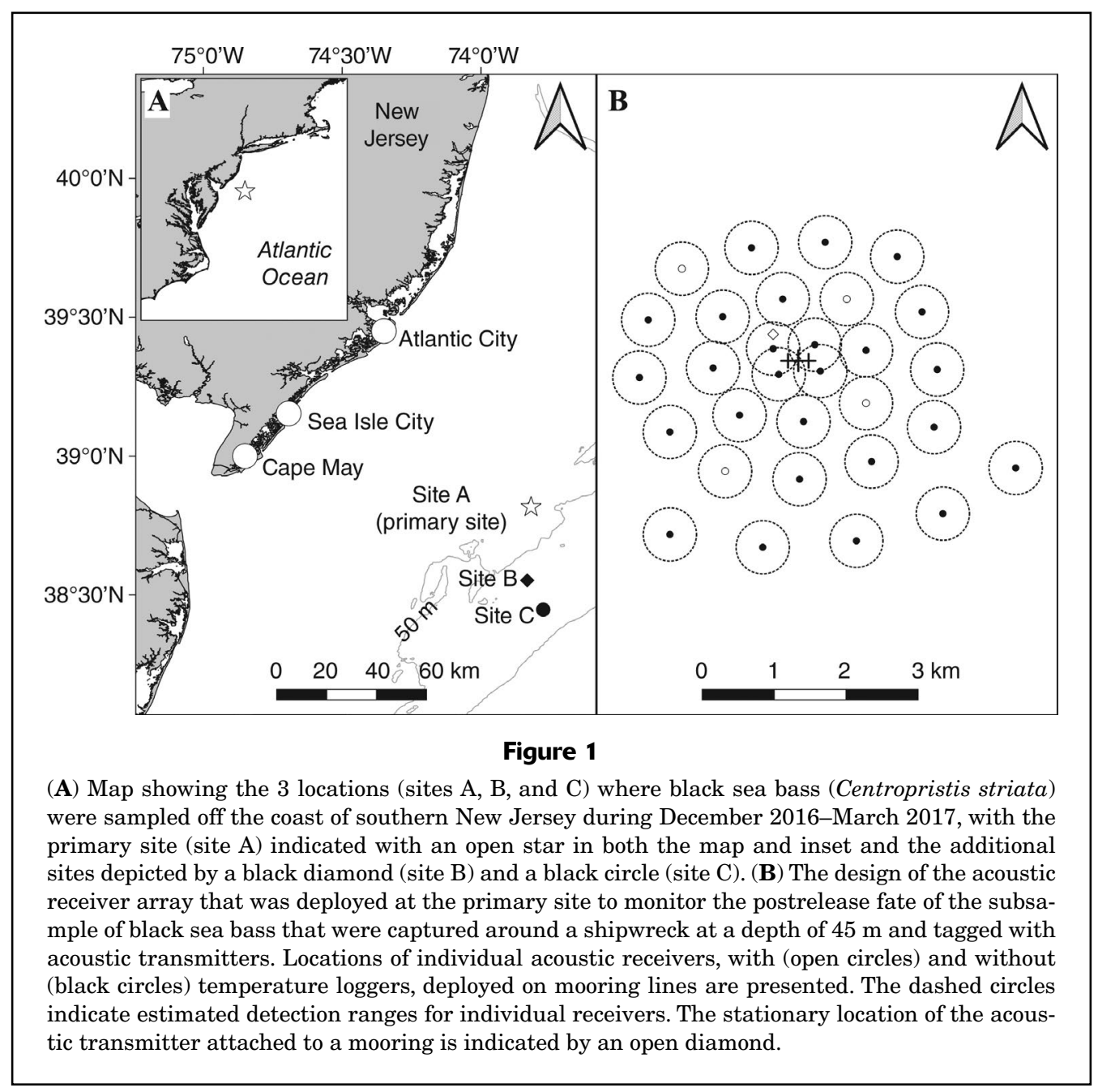

The sampling of black sea bass occurred during for-hire charters aboard the head boats F/V Susan Hudson (vessel length: $17 \mathrm{~m}$ ) from Sea Isle City, New Jersey, and F/V Porgy IV (vessel length: $24 \mathrm{~m}$ ) from Cape May, New Jersey. Each sampling trip had 6-14 volunteer anglers and up to 4 scientific personnel. Prior to starting fishing activity, each volunteer angler was required to complete a questionnaire that quantified their experience level with respect to saltwater fishing in deep water (depths $>35 \mathrm{~m}$ ). For all fishing activities, volunteer anglers were provided with the standardized terminal tackle rig, the same bait (Atlantic surfclam, Spisula solidissima), and a lead sinker (284-567 g) appropriately sized for the sea conditions, and they were allowed to determine how best to fish, handle, and unhook their catch to promote authentic scenarios. For each captured black sea bass, a series of technical and biological variables that describe the capture event were recorded (Table 1). Each volunteer angler was provided a stopwatch to record fight time, unhooking time, and handling time.

Anecdotal reports from anglers have suggested that the inability to submerge due to barotrauma is a major contributor to discard mortality. Previous research has indicated that swim bladder venting can reduce the rate of discard mortality for black sea bass captured at depths of 42-55 m off South Carolina (Collins et al., 1999). Therefore, to examine the efficacy of swim bladder venting for reducing discard mortality of black sea bass, a subset of fish was vented by using a Ventafish VF-1 Fish Venting Tool (Big Pond Products LLC, Tallahassee, FL) with a 16-gauge replaceable needle and $45^{\circ}$ beveled front end. To standardize the methods, all fish were vented by a single trained scientist by placing the fish flat on a measuring board and inserting the needle into the swim bladder behind the pectoral fin following directions provided by the manufacturer. This approach was taken to examine the potential benefit of proper venting technique and to avoid potential bias that may occur from improper venting (Wilde, 2009).

\section{Tagging procedure and postrelease fate monitoring}

To monitor postrelease fate, a subsample of 96 black sea bass captured at site A (depth: $45 \mathrm{~m}$ ) were externally tagged through the dorsal musculature with $69-\mathrm{kHz}$ pressure-sensing VEMCO acoustic transmitters equipped 


\section{Table 1}

Description of the technical, biological, environmental, and physical capture-related variables recorded for each captured black sea bass (Centropristis striata). The sampling of black sea bass occurred during for-hire charters operating from Sea Isle City and Cape May, New Jersey, between December 2016 and March 2017. Exopthalmia is an effect of barotrauma.

Variable (unit)

Description

Technical

Capture depth $(\mathrm{m})$

Angler experience

Fight time (s)

Unhooking time (s)

Handling time (s)

Hook location

Hook removal method

Biological

Total length (mm)

Release behavior

Environmental

Air temperature $\left({ }^{\circ} \mathrm{C}\right)$

Surface temperature $\left({ }^{\circ} \mathrm{C}\right)$

Bottom temperature $\left({ }^{\circ} \mathrm{C}\right)$

Delta temperature $\left({ }^{\circ} \mathrm{C}\right)$

Physical

Injury

Exopthalmia

Stomach eversion
Water depth at the location of capture

Angler experience score as classified by questionnaire (i.e., experienced or inexperienced)

Elapsed time from when a fish was hooked to when it reached the surface

Elapsed time from surfacing until the fish was unhooked

Elapsed time from surfacing until fish was released (time out of water)

Mouth; body (foul hooked)

Angler hand; mate hand

Length from the tip of the snout to the tip of the center of the tail

Floating; swimming down; erratic swimming; sinking

On deck temperature at the time of capture

Water temperature at the surface

Water temperature at the bottom or at the wreck

Difference between surface and bottom water temperatures

Present (1, >2 cm in length); absent (0)

Present (1); absent (0)

None (0); in mouth (1); protruding from mouth (2); ruptured (3) with end caps (model V9P-2H, VEMCO, Bedford, Canada; dimensions: $29 \mathrm{~mm}$ long with 9 -mm diameter; battery life: $673 \mathrm{~d}$; pressure sensor maximum depth: $204 \mathrm{~m}$; sensor resolution: $0.9 \mathrm{~m}$; sensor accuracy: $\pm 10 \mathrm{~m}$ ). Transmitters were affixed to each fish by attaching a short piece of $22.7-\mathrm{kg}$ monofilament to the transmitter's endcap and passing the monofilament through the dorsal musculature with a hypodermic needle. The transmitter was then secured in place by 2 Floy Petersen discs (Floy Tag Inc., Seattle, WA; 12.7-mm diameter) positioned on each side of the body (Fig. 2). Prior to at-sea sampling, a holding tank study was performed on captive black sea bass; this study confirmed that this attachment method resulted in no tag shedding or tagging-induced mortality over a 62 -d period. Transmitters were programmed with a stepwise series of nominal transmission delay ( $120 \mathrm{~s}$ for $0-15 \mathrm{~d}$; $300 \mathrm{~s}$ for $15-673 \mathrm{~d}$ ). An equal number of vented and non-vented fish were tagged with acoustic transmitters (number of samples $[n]=48$, per treatment), and efforts were made to vent fish over all observed lengths and in an equal ratio across representative fishing conditions.

An array of 30 VEMCO VR2W 69-kHz acoustic receivers was strategically deployed around the shipwreck at site A to monitor the movements of black sea bass tagged with acoustic transmitters (Fig. 1B). To evaluate receiver detection range, a single V9P-2H transmitter was deployed on the bottom at a fixed location near the center of the array from January through March 2017. Analysis of detection data from this transmitter estimated the mean detection range (i.e., $50 \%$ probability of detection) to be $300 \mathrm{~m}$ (Winton et al., 2018). Twenty-five receivers were deployed for 119 d (28 November 2016-27 March 2017), and an additional 5 receivers were deployed for $69 \mathrm{~d}$ (17 January 2017-27 March 2017) along the southern extent of the array to better monitor fish emigration. HOBO Pendant temperature loggers (Onset Computer Co., Bourne, MA) were placed at the surface and bottom of the mooring lines of 4 receivers (Fig. 1B) and were programmed to record water temperature every 5 min (Table 1). Receivers were downloaded and cleaned every $30-45 \mathrm{~d}$. Three receivers were lost during the study period.

To identify detection patterns indicative of a dead fish (i.e., continuous presence on the seafloor; see Yergey et al., 2012, and Capizzano et al., 2016), detection data were collected for 2 black sea bass that were intentionally sacrificed, tagged with acoustic transmitters, and released at the seafloor by using a descending device to minimize the risk of predation on the carcasses. These fish served as negative controls, and their detection histories were used to help identify mortality events in fish tagged with acoustic transmitters. In contrast, movement data obtained for 7 acoustically tagged black sea bass that were confirmed to be alive, either by acoustic detection in the Atlantic Cooperative Telemetry Network $(n=4)$ or fishery-dependent recapture $(n=3)$, were used as positive controls to distinguish behavior of black sea bass known to be alive. 

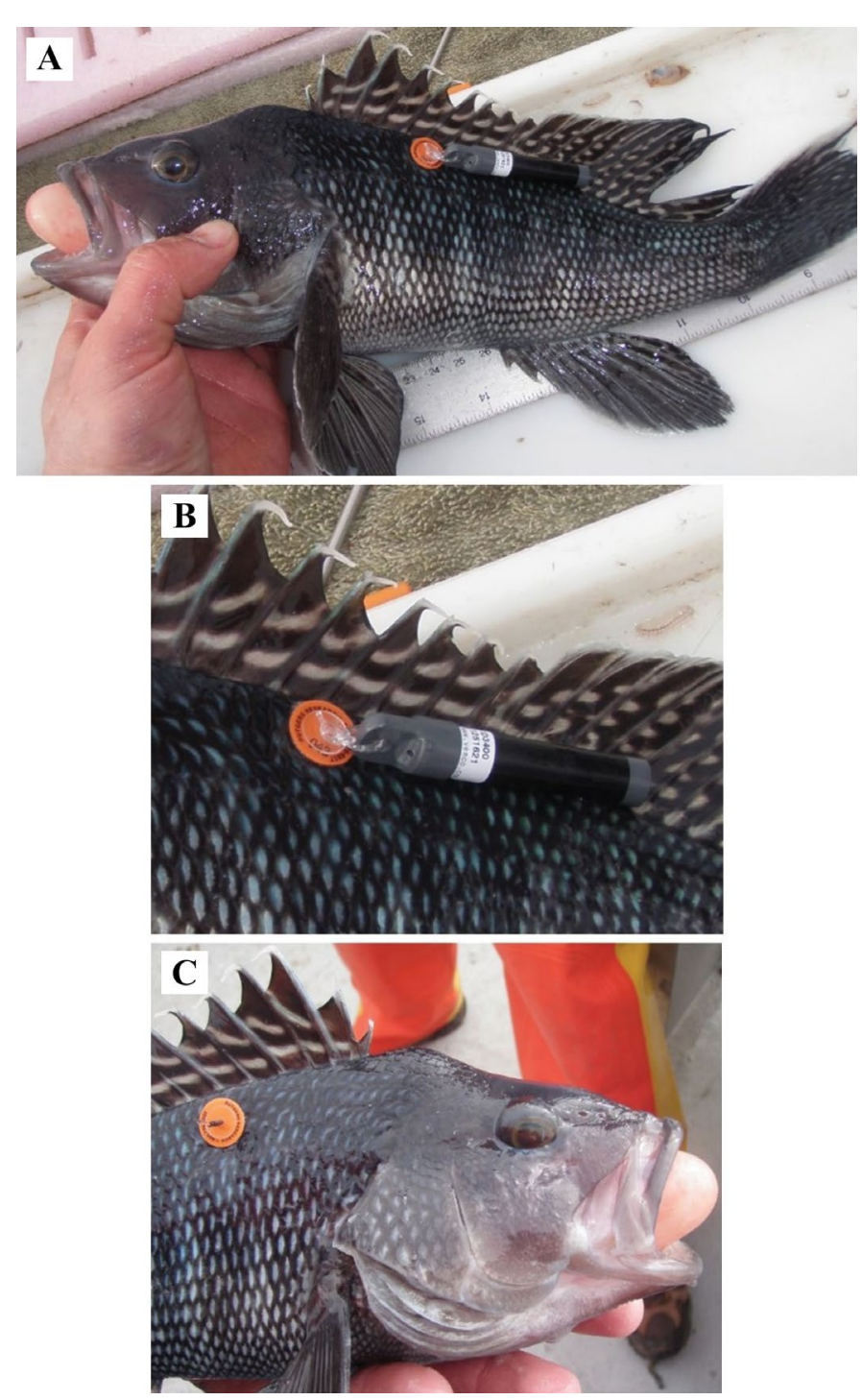

Figure 2

(A) Photograph of a black sea bass (Centropristis striata) externally tagged with an acoustic transmitter during this study. Fish were sampled for acoustic tagging off the coast of southern New Jersey from December 2016 through February 2017. A VEMCO V9P-2H acoustic transmitter with end caps is rigged with $22.7-\mathrm{kg}$ monofilament and passed through the dorsal musculature of the tagged fish. Floy Petersen discs hold the tag in place on both sides of the fish: (B) one side is attached to the tag, and (C) the other side has a copper crimp that secures the tag in place. small sample sizes $(\triangle \mathrm{AICc})$ of 3 units or more (Burnham and Anderson, 2002) according to Benoît et al. (2010). Given the potential effect of individual angler behavior on results, an angler covariate was included as a random effect in all mixed-effect models to account for within-cluster correlation (e.g., Benoît et al., 2010; Knotek et al., 2018). All statistical analyses were performed in R (vers. 3.5.2; R Core Team, 2018), and statistical significance was accepted at a level of $P<0.05$.

Capture characteristics To investigate the relationship between fight time and several variables, including fish total length (TL), capture depth, capture as part of an event referred to as a double header (i.e., 2 fish captured simultaneously, 1 fish on each hook), and reel ratio (i.e., high or low speed reels), a generalized additive mixed-effect model with an inverse link function was performed by using the $\mathrm{R}$ package mgcv, vers. 1.8-26 (Wood, 2011). A mixed-effect logistic regression was also employed to evaluate the relationship between release behavior and several capture-related variables, including capture depth, TL, physical injury, presence of exopthalmia, presence of stomach eversion, and venting treatment.

Fate assessment The fate (i.e., alive or dead) of individual black sea bass tagged with acoustic transmitters was assessed by comparing vertical and horizontal movements against those of positive and negative controls. Prior to analysis, all transmitter data were initially vetted for false detections by using the false detection analyzer tool in VEMCO's User Environment (vers. 2.2.2) and irrational detection data that coincided with potential transmitter failures. Given the effect of misclassified mortality events in longitudinal survival analyses (described later), we employed a 3-step approach to determine the fate of individual fish. Step 1 involved the use of a discriminant function analysis, which creates a function capable of classifying individuals of unknown fate into groups based on metrics from individuals with known fates (White and Ruttenberg, 2007) by using solely acoustic detection data. A discriminant function was created by using gross movement metrics from positive and negative controls, specifically maximum depth variance, minimum depth, and the proportion of total depth observations that were shallower than an individual's mean overall observed depth minus the mean depth variance of the dead control fish. The discriminant function was executed by using the MASS package (vers. 7.3-45; Venables and Ripley, 2002) in $R$ and resulted in a fate assignment for each fish.

Step 2 included the application of a variance test on depth observations recorded at defined intervals throughout the
A suite of models was employed to evaluate the effect of capture-related variables on discard mortality of black sea bass. Model selection procedures for identifying the most parsimonious model for each analysis in this study followed a stepwise forward selection procedure based on changes in the Akaike information criterion corrected for 
detection history of each acoustically tagged fish (Capizzano et al., 2016, 2019). Only intervals with at least 10 observations were included in the analysis. To account for the effect of tide height on individual depth observations, the tidal cycle at site A was estimated and removed from each transmitter's depth record by using package oce (vers. 09-21; Kelley and Richards, 2017). The variance of tide-corrected depth observations in each time interval was individually compared with that of the negative controls for each fish by using a 1-tailed $t$-test of the absolute difference from the median (modified Browne-Forsythe test for homogeneity of population variance; Ott and Longnecker, 2010), hereafter referred to as the depth-variance test. Because of the occurrence of off-bottom movements in black sea bass, when the depth variance of a tagged fish was significantly different $(P<0.05)$ from the negative controls during one or more time intervals, the fish was classified as being alive.

Following steps 1 and 2, all fish that were detected for $>2 \mathrm{~d}$ and had the same fate predicted by both the discriminant analysis (i.e., step 1) and depth-variance test (i.e., step 2) ( $n=50)$ were assigned the appropriate fate. The final fate of the remaining detected fish $(n=44)$, because of the brevity of their monitoring period (i.e., the lack of critical movement data for the depth-variance test) or the discrepancy between the discriminant analysis and depth-variance results, was determined in step 3 by using 1) a semiquantitative assessment of the horizontal and vertical movement patterns of each fish that placed particular emphasis on the comparison of their movements to those evident in both positive and negative controls and 2) an analysis of each fish's horizontal trajectory in relation to surface and bottom currents estimated at the study site by the Regional Ocean Modeling System (ROMS, vers. 3.6; Allen et al., 2003; ROMS/TOMS Group, 2013).

Briefly, if a fish's general pattern of movement was characterized by bottom-oriented behavior with some vertical movements and nonlinear horizontal emigration from the receiver array, it was considered to be alive. Fish were considered dead if they consistently remained at depth (i.e., on the seafloor) and made horizontal movements restricted to a straight line in the direction of the prevailing bottom current predicted by the ROMS model. In some instances, transmission data indicate more rapid horizontal movements and more frequent vertical movements of greater magnitude (i.e., $15-20 \mathrm{~m}$ off bottom) than were apparent in positive controls. These instances were considered predation events, a characterization that is consistent with reports from industry collaborators and with observations recorded during tagging that some fish are consumed by predators while being reeled up to the surface or while resubmerging postrelease. All fish with events identified as predations were included in the survival analysis as dead fish.

Longitudinal analysis Because the continuous acoustic monitoring of tagged black sea bass identified the time when fish either died or were last observed to be alive (i.e., longitudinal data), traditional survival analyses were used to address 2 objectives following procedures outlined by Knotek et al. (2018). The first objective was to evaluate the suitability of recorded capture-related variables (i.e., covariates) for predicting survival and then identify a parsimonious subset of those covariates that best predict survival. The second objective was to use this subset of covariates to assess whether potential models were capable of describing the survival function (i.e., cumulative probability of survivorship over time; Cox and Oakes, 1984) and estimating discard mortality of tagged black sea bass.

Evaluation of relevant capture-related factors for survival A combination of nonparametric and semiparametric longitudinal survival analyses were used to address the first objective. First, the empirical and nonparametric Kaplan-Meier (KM) estimator was used to visually explore the individual effect of capture-related covariates (Table 1) on the survival function (Cox and Oakes, 1984). For instances in which a categorical covariate had more than 2 groupings, and thus survival functions, the Peto-Peto modification of the Gehan-Wilcoxon logrank test was used to evaluate if 2 or more survival functions were statistically different (Harrington and Fleming, 1982).

By reviewing the output of $\mathrm{KM}$ estimator plots and logrank tests, 6 sensible covariates were selected a priori as variables that potentially influence discard mortality in black sea bass: fight time, handling time, TL, presence of physical injury, temperature differential between surface and bottom waters, and venting treatment. All other covariates that did not produce meaningful differences in their KM survival functions and log-rank tests were not considered and were dropped from the analysis. The release behavior covariate was dropped because of insufficient sample size among groups and its strong correlation with the venting treatment variable. Preliminary results from KM estimators and log-rank tests also support the categorization of various covariates, which was accomplished by either binning all continuous covariates of interest at their median value or combining groups in categorical covariates to produce meaningful associations (e.g., angler experience scores into experience categories). Such categorizations resulted in the addition of a 7 th covariate, the general season of capture (i.e., astronomical autumn and winter).

Despite the KM estimator's ability to track the proportion of individuals considered to be alive at each time interval in the absence of censored observations, it provides a univariate analysis. Therefore, to objectively evaluate the additive effect of multiple covariates as predictors of survival, a mixed-effect Cox proportional hazards model (CPHM) was used to address the first objective (Cox, 1972; Therneau and Grambsch, 2000). A suite of CPHMs that incorporate all 7 covariates was constructed, and the CPHMs were compared by using a stepwise forward selection procedure with $\triangle \mathrm{AICc}$. Covariates that ultimately best fit the data were retained and used in the 
second objective to both describe the survival function and estimate discard mortality.

Predicting discard mortality with relevant covariates Regardless of their ability to fit the data, nonparametric and semiparametric models cannot be used to parse out different mortality sources (e.g., capture and handling mortality and postrelease mortality) or provide mechanistic interpretations of survivorship patterns over time (Benoît et al., 2015). Therefore, the parametric modeling approach developed by Benoît et al. (2015) was used because of its ability to explicitly account for these types of mortality and to provide estimates for each. The survival function for this model, the probability of surviving to time $S(t)$, is expressed with the following equation:

$$
S(t)=\tau \times\left\{\pi \times \mathrm{e}^{-[\alpha \times \mathrm{t}]^{\gamma}}+(1-\pi)\right\},
$$

where $\tau=$ the probability of surviving capture and handling;

$\pi=$ the probability that an individual was adversely affected by the fishing event postrelease; and

$\alpha$ and $\gamma=$ the scale and shape parameters, respectively, of an underlying Weibull distribution that determines the mortality patterns over time for adversely affected individuals.

From this equation, we can understand that when $t$ is 0 , $S(t)$ is equal to $\tau$. Therefore, as $t$ increases to $\infty$, the expression $\tau \times \pi \times \mathrm{e}^{-[\alpha \times \mathrm{t}]^{\gamma}}$ decreases to 0 (i.e., all affected fish die) and $S(t)$ becomes $\tau(1-\pi)$ (i.e., only unaffected individuals remain alive). Additional details and justification of this model, including the use of maximum likelihood methods for fitting the data to the model, are provided in Benoît et al. (2012, 2015), and examples of this equation can be found in Capizzano et al. (2019).

After determining the basic model and appropriate terms to include, model variants of this equation were developed and fit with covariates of interest to address the second objective. The influence of covariates from the first objective that may affect survival are often introduced on $\tau$ and $\pi$ terms in the model (e.g., Capizzano et al., 2016, 2019). Three model variants of this equation therefore were fit to the data (Table 2) and visually assessed by superimposing predicted survival functions on the KM estimates and $95 \%$ confidence intervals (CIs). Relative fit between model variants and selected covariates was quantified and compared with the stepwise forward selection procedure by using $\triangle \mathrm{AICc}$ as previously described.

Evaluating relevant covariates for unvented subsample The nonparametric KM estimator and semiparametric CPHM survival analyses were also applied to data for unvented fish in the subsample of fish tagged with acoustic transmitters to examine the suitability of other covariates for predicting survival. Six sensible covariates previously included in the mixed-effect CPHM selection procedure were selected a priori and with evidence from KM estimators: fight time, handling time, TL, presence of physical injury, temperature differential between bottom and surface waters, and general season of capture (i.e., astronomical fall and winter). The angler covariate was included as a random effect. Despite the strengths of the parametric Weibull mixture distribution modeling approach described earlier, only the mixed-effect CPHM modeling procedure was used because sample sizes of fish were halved when examining only unvented fish.

\section{Table 2}

Three variants of the survival model developed by Benoît et al. (2015) to analyze the survivorship of black sea bass (Centropristis striata) over time and fit to data from sampling conducted off southern New Jersey between December 2016 and February 2017. Assumptions for parameters of the equation used to express the survival function (see the "Data analysis" section), specifically the probability of surviving capture and handling $(\tau)$ and the probability of being adversely affected by the fishing event postrelease $(\pi)$, were used to define the 3 competing model variants. $X=$ the design matrix for the covariates; $\beta=$ the vector of parameters for the effect of the covariates.

\begin{tabular}{lcl}
\hline Variant & Parameters & Description \\
\hline 1 & $\tau=\left[1+e^{\left(-\mathrm{X}^{\prime} \beta_{1}\right)}\right]^{-1}$ & $\begin{array}{r}\text { Covariate effects on the probability of surviving capture } \\
\text { and handling and the probability of being adversely } \\
\text { affected by the fishing event postrelease }\end{array}$ \\
$\pi$ & $=\left[1+e^{\left(-\mathrm{X}^{\prime} \beta_{2}\right)}\right]^{-1}$ & $\begin{array}{c}\text { Covariate effect on only the probability of being adversely } \\
\text { affected by the fishing event postrelease }\end{array}$ \\
3 & $\pi=\left[1+e^{\left(-\mathrm{X}^{\prime} \beta_{3}\right)}\right]^{-1}$ & $\begin{array}{c}\text { Covariate effect on only the probability of surviving } \\
\text { capture and handling }\end{array}$
\end{tabular}




\section{Results}

\section{Capture characteristics}

Fifty volunteer anglers captured 1823 black sea bass (size range: $136-612 \mathrm{~mm}$ TL) (Table 3 ). Given the federal minimum landing size of $317.5 \mathrm{~mm}$ TL in $2017,40 \%$ of the sampled fish would have been smaller than the legal limit. Forty-three anglers (86\%) were classified as being experienced on the basis of their answers to our questionnaire and were responsible for the capture of $92 \%$ of the sampled fish. Capture-related variables were recorded for all fish with the exception of 110 fish that were retained for an aging experiment and had no venting status or release behavior recorded. A total of 957 fish had their swim bladder vented before release; 756 fish were released unvented. There were 321 capture events classified as a double header. The majority of fish $(92 \%)$ were hooked in the mouth, but some fish were also foul-hooked in various locations of the body.

A total of 304 black sea bass (17\%) incurred injuries (i.e., wounds $>2 \mathrm{~cm}$ ), mostly as a result of hooking trauma or the hook removal process. Twelve individuals $(<1 \%)$ were dead upon landing, with most of them $(n=8)$ having been bitten in half following predation by other fish. The vast majority of captured black sea bass (95\%) exhibited effects of barotrauma, with a stomach eversion score of 2 (i.e., stomach protruding from the mouth cavity) present in $68 \%$ of all captured fish. Barotrauma effects were generally more prevalent in fish coming from greater depths, particularly exopthalmia, which was most prevalent at the deepest capture depth (Fig. 3).

Released black sea bass exhibited 4 behaviors, with the vast majority either swimming down (74\%) or floating $(25 \%)$. Only a small number of fish swam erratically $(<1 \%)$ or sank $(<1 \%)$. The prevalence of floating behavior was greater in fish captured at greater depths (Fig. 3).

Strong evidence from this study indicates that fight time increased in response to TL, capture depth, capture as part of a double header, and reel ratio (Table 4). Depth was the most influential factor affecting fight time, with fish captured at the deepest depth $(67 \mathrm{~m})$ experiencing the longest fight times. At each depth, interpolation of mean fight time indicates that fish $>491 \mathrm{~mm}$ TL fought for longer than average durations. The results of a mixed-effect logistic regression indicate that $\mathrm{TL}$, capture depth, venting, and the presence of exopthalmia weakly influenced release behavior, with fish having a lower probability of swimming down if they were larger in size, not vented, caught at greater depths, and experienced exopthalmia (Table 4, Fig. 4).

\section{Table 3}

Summary of capture variables from observations for all 1823 sampled black sea bass (Centropristis striata), including those for the 96 fish that were tagged with acoustic transmitters. Black sea bass were sampled off southern New Jersey between December 2017 and March 2017 at 3 sites with varying depths of capture $(45,58$, and $67 \mathrm{~m})$. Two methods of hook removal were used: angler hand and mate hand. Mean values are provided with standard deviations (SDs) in parentheses. The federal legal size limit for capture of black sea bass was $317.5 \mathrm{~mm}$ TL in 2017 . An asterisk (*) indicates that water temperatures were available only for the primary site, a shipwreck located $\sim 85 \mathrm{~km}$ southeast of Sea Isle City, New Jersey.

\begin{tabular}{lccccc}
\hline & \multicolumn{2}{c}{ Tagged fish } & & \multicolumn{2}{c}{ All observations } \\
\cline { 2 - 3 } \cline { 5 - 6 } Variable (unit) & Range & Mean (SD) & & Range & Mean (SD) \\
\hline Total length (mm) & $278-546$ & $354(57)$ & & $136-612$ & $339(70)$ \\
No. fish at legal vs. non-legal size & - & - & & $1089 / 722$ & - \\
$45 \mathrm{~m}$ & $64 / 32$ & - & & $199 / 359$ & - \\
$58 \mathrm{~m}$ & - & - & & $405 / 47$ & - \\
$67 \mathrm{~m}$ & - & - & & $485 / 316$ & - \\
Fight time (s) & $17-225$ & $56(24)$ & & $12-251$ & $78(32)$ \\
$45 \mathrm{~m}$ & $17-225$ & $56(24)$ & & $12-225$ & $55(22)$ \\
$58 \mathrm{~m}$ & - & & & $32-240$ & $80(27)$ \\
$67 \mathrm{~m}$ & - & & & $35-251$ & $94(30)$ \\
Unhooking time $(\mathrm{s})$ & $2-52$ & $15(11)$ & & $10-215$ & $17(19)$ \\
Angler hand & $2-49$ & $15(11)$ & & $1-215$ & $18(20)$ \\
Mate hand & $3-52$ & $15(12)$ & & $2-173$ & $17(17)$ \\
Experienced anglers & $2-52$ & $14(11)$ & & $1-189$ & $17(19)$ \\
Inexperienced anglers & $13-36$ & $29(9)$ & & $2-215$ & $19(21)$ \\
Handling time $(\mathrm{s})$ & $80-326$ & $164(51)$ & & $13-575$ & $142(81)$ \\
Air temperature $\left({ }^{\circ} \mathrm{C}\right)$ & $5.9-15.1$ & $10.7(2.3)$ & & $4.7-17.4$ & $13.9(2.4)$ \\
Sea surface temperature $\left({ }^{\circ} \mathrm{C}\right)$ & $7.4-13.8$ & $11.4(2.1)$ & & $7.2-13.9 *$ & $12.4(1.7)^{*}$ \\
Bottom temperature $\left({ }^{\circ} \mathrm{C}\right)$ & $7.4-13.8$ & $11.3(2.0)$ & $7.5-13.4^{*}$ & $12.2(1.4)^{*}$ \\
Delta temperature $\left({ }^{\circ} \mathrm{C}\right)$ & $-0.6-0.4$ & $0.1(0.3)$ & $-0.3-0.5^{*}$ & $0.3(0.3)^{*}$ \\
& & & & \\
\hline
\end{tabular}



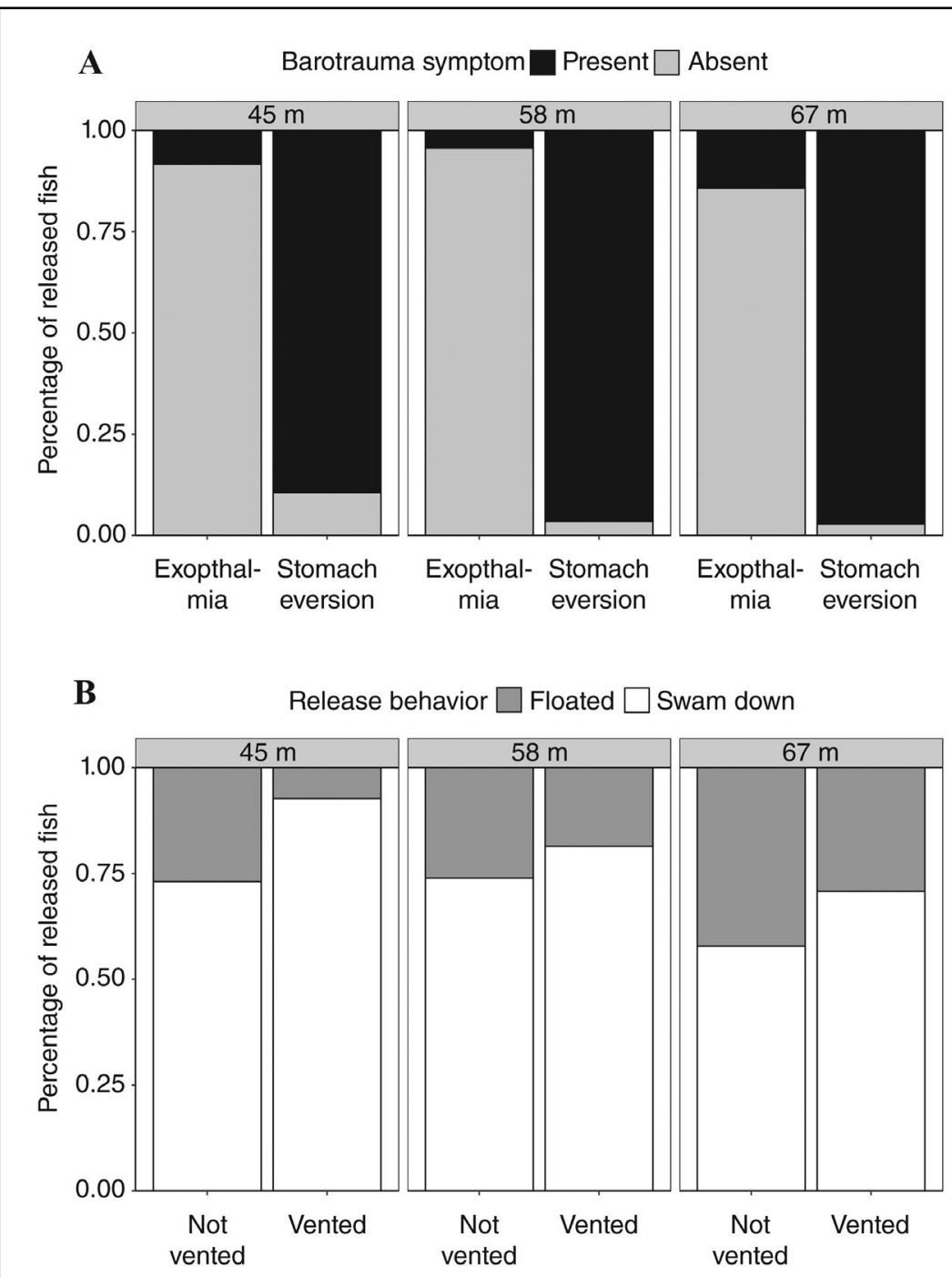

Figure 3

Stacked histograms depicting the prevalence of (A) barotrauma effects and (B) release behaviors of black sea bass (Centropristis striata) as a function of the depth (in meters) at which fish were sampled off southern New Jersey between December 2016 and March 2017. Stomach eversion was considered to be present if a fish was assigned a stomach eversion score of 1 (stomach everted but not protruding from mouth cavity), 2 (stomach everted and protruding from the mouth cavity), or 3 (stomach ruptured). Prevalence of behaviors is compared between fish that had their swim bladder vented and those that did not. monitoring period, and the single fish that was detected within the acoustic array on the last day of monitoring (3 March 2017) was later detected by a receiver array off Maryland, confirming its survival. Of the 33 mortalities, $9(27 \%)$ were attributed to predation following resubmergence (i.e., as the animal descended toward the seafloor or after it reached the seafloor). All predation events occurred between 1.8 and $18.4 \mathrm{~h}$ (mean: $7.2 \mathrm{~h}$ [standard deviation (SD) 4.5]) postrelease. The remaining 24 mortalities were assumed to have occurred as a result of the fishing event and occurred 5.0-128.0 h (mean: $17.1 \mathrm{~h}$ [SD 26.7]) postrelease (95.8\% of mortality occurred within $72 \mathrm{~h}$ ).

When examining the entire subsample of black sea bass for which acoustic data are available $(n=94)$, the effect of venting treatment covariate was the only significant predictor of survival (CPHM approach; $\triangle \mathrm{AIC}$ : 4.84 ) that primarily influenced the probability that a fish was adversely affected by the fishing event postrelease (Weibull mixture distribution modeling approach; Table 5, model variant 2). Most of the mortality of black sea bass was estimated to have occurred postrelease (Table 6), with mean rates of discard mortality for non-vented fish (49\%; 95\% CI: $32-63 \%$ ) nearly 2.5 times greater than the rates for vented fish $(20 \% ; 95 \%$ CI: 11-35\%) (Fig. 5).

With respect to the non-vented black sea bass $(n=46)$ in the subsample, a mixed-effect CPHM found that the fight time variable best predicted survival for unvented fish ( $\triangle \mathrm{AICc}$ : 7.27). The CPHM's hazard ratio indicates that fight time was positively associated with the event probability (i.e., increased fight times increase the chance of mortality; $P<0.05)$. For example, when the median fight time value (54 s) was used as a cutoff to form 2 groups, non-vented black sea bass that experienced fight times

\section{Survivorship assessment}

Acoustic detection data were obtained for 94 of the 96 tagged black sea bass. The 2 fish that were not detected by the array were floating after release and were among the smallest individuals to be tagged with acoustic transmitters (286-287 mm TL). Of the 94 detected fish, 61 survived the capture, handling, and release processes and 33 died after release. Of those fish considered to be alive, 60 emigrated from the receiver array during the
$>54 \mathrm{~s}$ were estimated to suffer roughly $74 \%$ mortality, a much higher rate than the $29 \%$ mortality estimated for fish with fight times $\leq 54 \mathrm{~s}$ (Fig. 6).

\section{Discussion}

Our results indicate that swim bladder venting, when done correctly, reduced the discard mortality rate for black sea bass by almost $30 \%$ following capture at a depth of $45 \mathrm{~m}$. 


\section{Table 4}

Results of forward model selection for the generalized additive mixed-effect model used to examine the relationship between the capture-related variables and fight time and for the mixed-effect logistic regression model that evaluated release behavior against a set of sensible covariates for all released black sea bass (Centropristis striata) $(n=1594)$. Covariates that produced a reduction of 3 or more units in the Akaike information criterion corrected for small sample sizes (AICc) from the previous model were retained. Values for the change in AICc from the previous candidate model $(\triangle \mathrm{AICc})$ are provided. Data used in the models are from sampling of black sea bass conducted off southern New Jersey between December 2016 and March 2017. An asterisk (*) indicates the model that best fits the data. Exopthalmia is an effect of barotrauma. TL=total length; DH=double header, an event when 2 fish are captured simultaneously, 1 fish on each hook.

\begin{tabular}{lccrr}
\hline & $\begin{array}{c}\text { Estimated } \\
\text { Mf }\end{array}$ & $\begin{array}{c}\text { Deviance } \\
\text { explained (\%) }\end{array}$ & AICc & $\Delta$ AICc \\
\hline Fight time & & & & \\
$\sim 1$ & 47.32 & 49.91 & 15688.16 & 595.88 \\
$\sim$ s(TL) & 48.29 & 54.24 & 15531.77 & 439.49 \\
$\sim$ s(TL) + depth & 49.46 & 63.10 & 15150.16 & 57.88 \\
$\sim$ s(TL) + depth + DH & 50.64 & 64.04 & 15105.86 & 13.58 \\
$\sim$ s(TL) + depth + DH+ reel gear* & 51.52 & 64.30 & 15092.28 & 0.00 \\
Release behavior & & & & \\
$\sim 1$ & 47.32 & 1.98 & 1832.16 & 95.28 \\
$\sim$ Depth & 48.29 & 2.90 & 1783.03 & 49.13 \\
$\sim$ Depth + venting & 49.46 & 4.97 & 1747.24 & 35.79 \\
$\sim$ Depth + venting + TL & 50.64 & 5.47 & 1740.04 & 7.20 \\
$\sim$ Depth + venting + TL + exopthalmia* & 51.52 & 5.75 & 1736.88 & 3.16 \\
& & & & \\
\hline
\end{tabular}

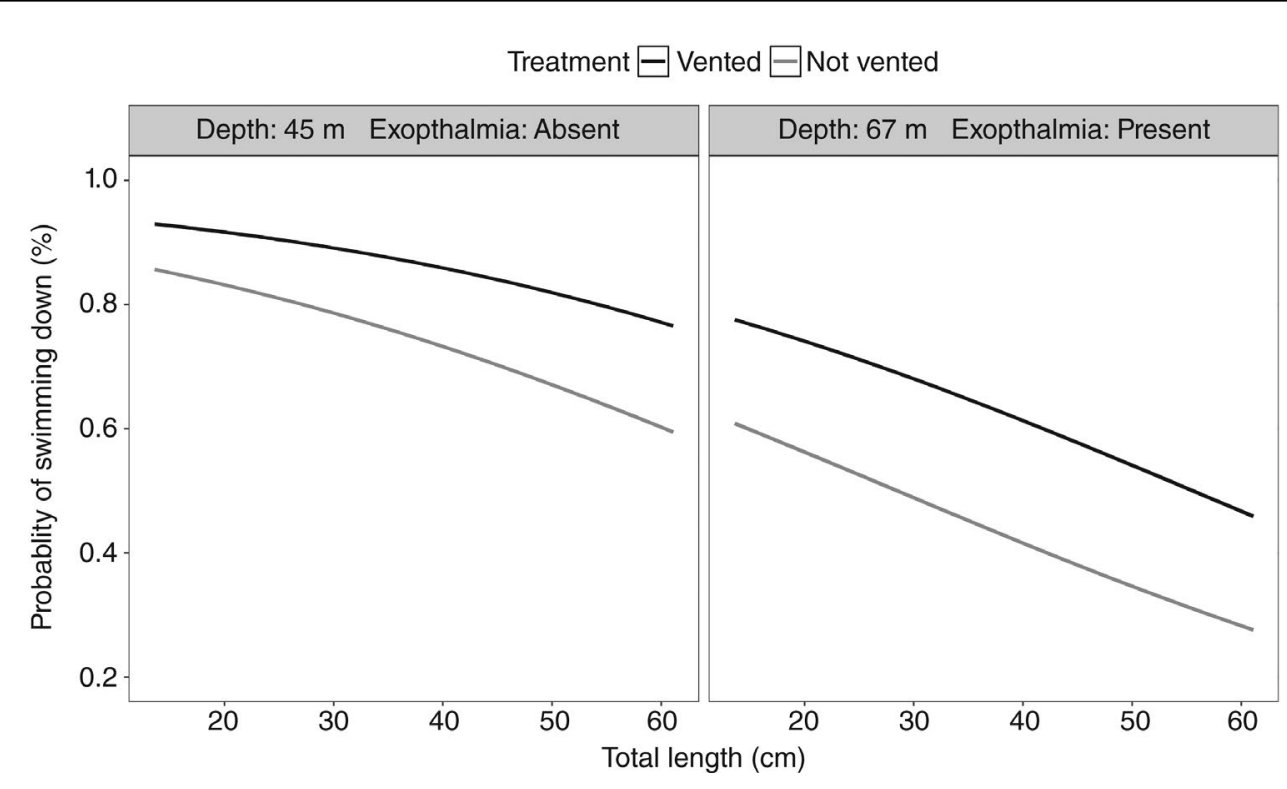

Figure 4

Probability that a released black sea bass (Centropristis striata) will actively swim down if it had its swim bladder vented (black line) or not vented (gray line), and how that probability varies by total length, depth of capture, and the presence of exopthalmia. Data used to model the probabilities came from fish sampled off southern New Jersey during December 2016-March 2017. For simplicity, 2 plots illustrate the overall submergence probability of fish with no exophthalmia captured at a shallow depth ( $45 \mathrm{~m}$, left plot) in comparison to that of individuals with exopthalmia captured at a greater depth $(67 \mathrm{~m}$, right plot) by venting treatment and total length. 


\section{Table 5}

Summary of results of model variant and covariate selection that used maximum likelihood and a forward selection procedure for the subsample of black sea bass (Centropristis striata) tagged with acoustic transmitters ( $n=96)$. Black sea bass were sampled off southern New Jersey at a depth of $45 \mathrm{~m}$ between December 2016 and February 2017. Values for the Akaike information criterion corrected for small sample sizes (AICc) and for the change in AICc from the previous candidate model $(\triangle \mathrm{AICc})$ are provided. An asterisk (*) denotes that the strongest evidence was for variant 2 of the model, which included the effect of venting covariate on the probability that a fish was adversely affected by the fishing event postrelease.

\begin{tabular}{llccr}
\hline Run & Covariates & Variant & AICc & $\Delta$ AICc \\
\hline 1 & $\sim 1$ & - & 134.90 & - \\
$2^{*}$ & $\sim$ Venting & 2 & 129.40 & 5.50 \\
2 & $\sim$ Venting & 1 & 132.52 & 2.38 \\
2 & $\sim$ Venting & 3 & 146.05 & -11.15 \\
& & & & \\
\hline
\end{tabular}

These results are consistent with those from previous work that found that swim bladder venting reduced the discard mortality rate for black sea bass off South Carolina (Collins et al., 1999) and from a recent meta-analysis that found that swim bladder venting, as well as the use of descending devices, had positive effects and reduced discard mortality for fish of several species that experienced barotrauma (Eberts and Somers, 2017). Interestingly, the clear benefits of proper swim bladder venting presented herein are counter to previous assertions that this practice should be prohibited given the possibility that it may adversely affect the survival of fish captured from deep water (e.g., Wilde, 2009). Because of the detrimental effects of improper venting technique (e.g., Scyphers et al., 2013; Brownscombe et al., 2017), the benefit of swim bladder venting for reducing discard mortality of black sea bass in deepwater recreational fisheries will not be fully realized without the extensive education and training of recreational anglers on proper venting techniques. Accordingly, future research should evaluate the relative benefits of swim bladder venting against those of using descending devices for reducing discard mortality of black sea bass in order to develop recommendations for the most appropriate catch-and-release procedures, particularly given that $40 \%$ of the fish sampled were below the minimum landing size and would have been discarded under typical fishery scenarios.

Our collaborations with industry stakeholders in New Jersey indicate that offshore anglers or crewmembers on for-hire vessels that target black sea bass do not commonly practice swim bladder venting. Therefore, the estimate of $49 \%$ for the discard mortality rate of non-vented fish is most representative of the contemporary winter deepwater fishery when it operates at a depth of $45 \mathrm{~m}$ off New Jersey. This estimate of discard mortality is higher than previous estimates generated for non-vented fish captured over a similar depth range off South Carolina (39\% mortality at depths of 43-54 m; Collins et al., 1999). However, this discrepancy could be in part a result of the fact that Collins et al. (1999) monitored the postrelease fate of fish for only $24 \mathrm{~h}$ while they were in cages, where animals were shielded from predation. In contrast, our electronic tagging approach enabled accounting for mortality occurring because of postrelease predation by fish of other species and documentation of delayed mortality up to $128 \mathrm{~h}$ after release. It is also possible that differing estimates of discard mortality rate were influenced by varying environmental conditions (e.g., air or water temperatures) between our winter study off New Jersey and the study completed by Collins et al. (1999) off South Carolina.

\section{Table 6}

Sample sizes and estimates of key parameters for the analysis of survival data for black sea bass (Centropristis striata) that had their swim bladder vented after capture at a depth of $45 \mathrm{~m}$ off southern New Jersey between December 2016 and February 2017. The numbers of fish that died upon release (dead), died during capture and handling or immediately after release (left censored), and were last observed to be alive (right censored) are presented. Estimates of the capture and handling mortality rate $(1-\tau)$, the conditional postrelease mortality rate $(\tau \times \pi)$, and the total mortality rate associated with the fishing event (i.e., discard mortality; $1-\tau+\tau \times \pi)$ are presented by treatment group, with $95 \%$ confidence intervals provided in parentheses.

\begin{tabular}{|c|c|c|c|c|c|c|c|}
\hline \multirow[b]{2}{*}{ Treatment } & \multicolumn{4}{|c|}{ No. of samples } & \multicolumn{3}{|c|}{ Fishing mortality rates } \\
\hline & Total & Dead & Left & Right & $\begin{array}{l}\text { Capture and } \\
\text { handling }\end{array}$ & Postrelease & Total \\
\hline Vented & 48 & 9 & 1 & 38 & $\begin{array}{c}0.017 \\
(0.001-0.158)\end{array}$ & $\begin{array}{c}0.203 \\
(0.107-0.351)\end{array}$ & $\begin{array}{c}0.219 \\
(0.131-0.406)\end{array}$ \\
\hline Not vented & 46 & 18 & 5 & 23 & $\begin{array}{c}0.017 \\
(0.001-0.158)\end{array}$ & $\begin{array}{c}0.487 \\
(0.319-0.633)\end{array}$ & $\begin{array}{c}0.504 \\
(0.362-0.662)\end{array}$ \\
\hline
\end{tabular}




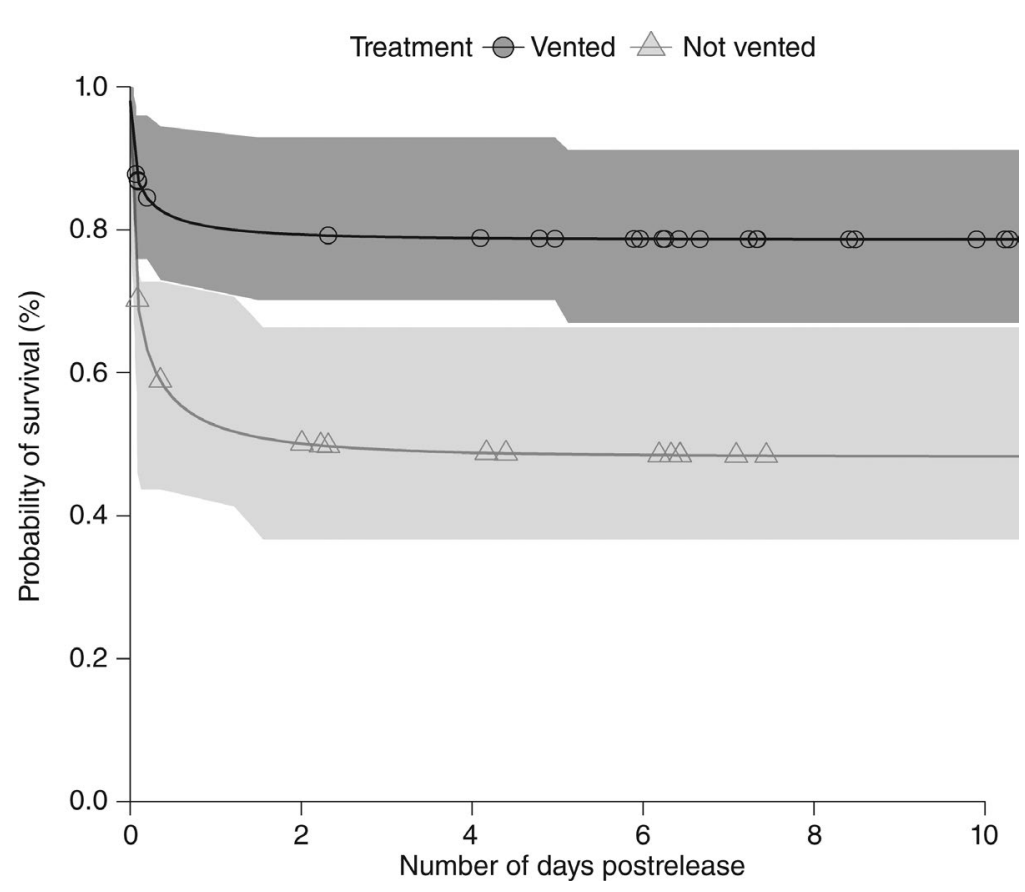

Figure 5

Nonparametric and model-based estimates of survival functions, cumulative probabilities of survival over time, for black sea bass (Centropristis striata) that had their swim bladders either vented (circles) or not vented (triangles) prior to release. Shaded areas indicate the $95 \%$ confidence interval for the estimates from the Kaplan-Meier survivor function, and the solid lines indicate estimates from the preferred survival model. The circles and triangles indicate the occurrence of observations in which the fish was last seen to be alive (right censored). The plot displays the fine-scale survival functions during the first $10 \mathrm{~d}$ after release, indicating that all of the discard-related mortalities were estimated to have occurred by day 5 given the asymptotic nature of the survival functions. Time zero is the time of release back into the water. Data used to produce estimates came from fish sampled off southern New Jersey from December 2016 through February 2017.

Postrelease predation had a noteworthy influence on the discard mortality rate for black sea bass, accounting for $27 \%$ of all documented mortality events. Results of previous research conducted off North Carolina indicates that predation of black sea bass during descent to the bottom may not greatly affect discard mortality (Rudershausen et al., 2014). However, on the basis of discussions with our industry collaborators and observations made during tagging, predation events can be common during the early part of the winter offshore fishing season off New Jersey (i.e., November and December) when predators, such as bluefish (Pomatomus saltatrix) and spiny dogfish (Squalus acanthias), are commonly present on the fishing grounds. Interestingly, no postrelease predation was observed for any acoustically tagged fish that was released after 21 December 2016, and no predation was observed during all trips to deeper fishing locations from mid-February through late-March of 2017. Therefore, predation on black sea bass by fish of other species both during capture and postrelease varied spatially and temporally, information that will be useful in consideration of fishery management options concerned with discards.

The practice of swim bladder venting was the single greatest predictor of discard mortality in the full subsample of fish tagged with acoustic transmitters, with unvented fish having lower submergence success than vented fish at all capture depths. Collectively, only $17 \%$ ( 2 out of 12 ) of the detected acoustically tagged fish that floated upon release ultimately survived, a rate that is consistent with the report by Rudershausen et al. (2014) that the inability to submerge did not result in $100 \%$ discard mortality. In addition, it is possible that the only 2 acoustically tagged fish not detected by any acoustic receiver experienced avian predation while floating at the sea surface. Avian predators, primarily herring (Larus argentatus) and great black-backed (Larus marinus) gulls, were abundant during the sampling trips during which these 2 fish were released, and these gulls were observed actively preying upon other released fish that did not have acoustic transmitters. Because the occurrence and prevalence of avian predation could not be fully accounted for during our study, actual discard mortality rates could be higher than those reported in this paper.

The latest stock assessments and fishery management plans for black sea bass assume a $15 \%$ discard mortality rate for the coast-wide, year-round black sea bass recreational fishery (NEFSC, 2017). Our results, as well as those of previous studies (e.g., Collins et al., 1999; Rudershausen et al., 2014), indicate that the discard mortality of black sea bass in deep waters is higher than the assumption that was applied in the last stock assessment. As a result, it is recommended that stock assessment scientists and fishery managers consider the higher discard mortality rates for deepwater fisheries in federal waters when quantifying total fishery removals and developing management measures. This is important for the winter offshore fishery because fishing effort and total catch during this season are not effectively monitored and estimates of discard mortality rates can factor heavily into different management options for recreational fisheries (e.g., the groundfish fishery in New England; Lee et al., 2017).

Our results add to the growing knowledge that capture depth has a large effect on discard mortality of black sea bass (e.g., Collins et al., 1999; Stephen and Harris, 2010; Rudershausen et al., 2014). For example, our estimate of the discard mortality rate for non-vented fish (49\%) was 


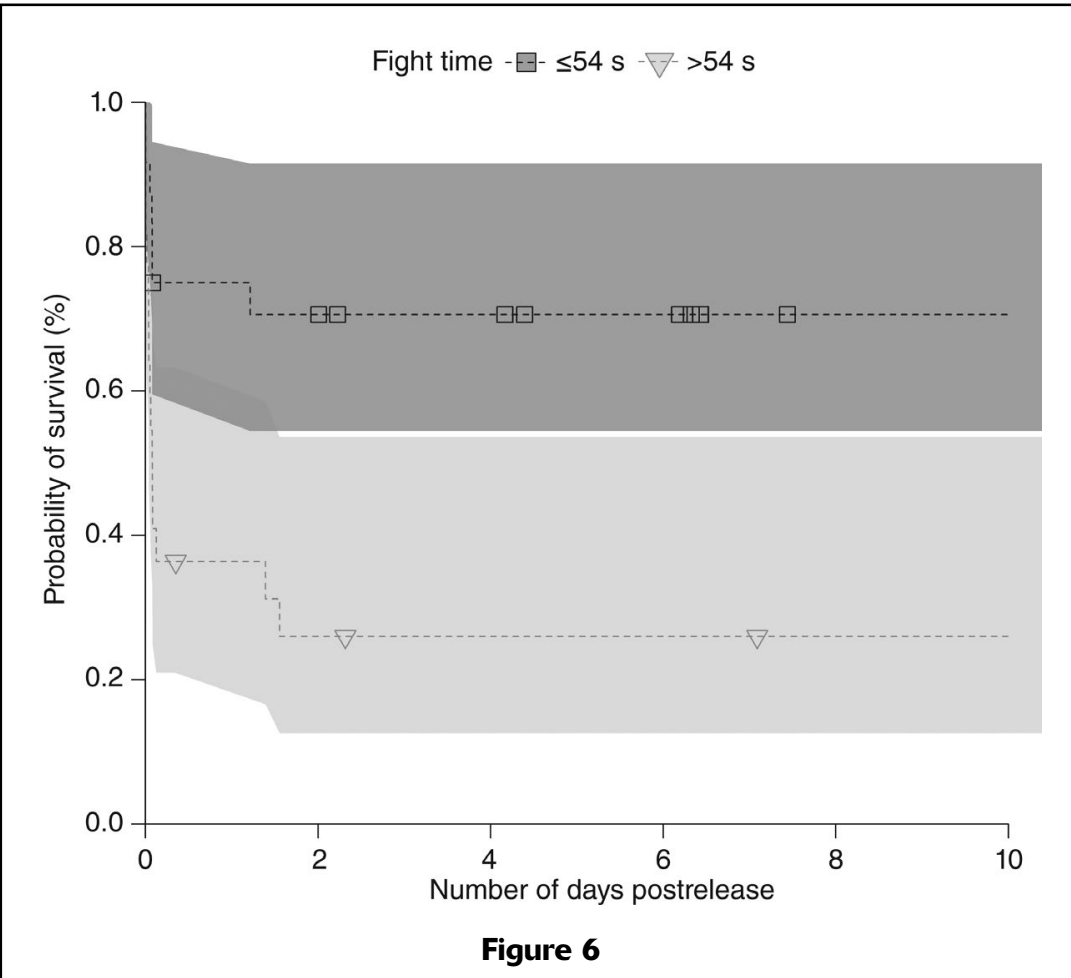

Plot of estimates (dashed lines) from the Kaplan-Meier survival function for black sea bass (Centropristis striata) in the subsample of fish tagged with acoustic transmitters that did not have their swim bladders vented $(n=46)$, by low ( $\leq 54 \mathrm{~s}$, squares) and high ( $>54 \mathrm{~s}$, triangles) fight times. Shaded areas indicate the $95 \%$ confidence interval of estimates, and squares and triangles indicate the time when an individual was last observed to be alive (right censored). The plot displays the fine-scale survival functions for the first $10 \mathrm{~d}$ after release and eventual asymptote in survival. Time zero is the time of release back into the water. Data used to produce estimates came from fish caught off southern New Jersey between December 2016 and February 2017. not found to be a significant predictor of discard mortality for black sea bass. The vast majority of individuals $(83 \%)$ did not experience hook trauma following a capture event, and there was a low incidence $(<1 \%)$ of deep or internal hooking in the esophagus, viscera, or gills. This low incidence of deep hooking may result from the use of a high-low terminal tackle rig with short leaders from the main line to each hook (i.e., dropper loops of 7.6-12.7 cm). As suggested by Capizzano et al. (2016), this configuration does not leave much opportunity for the fish to swallow the hook and therefore results in a high incidence of mouth hooking. The use of circle hooks, which have been reported to increase the incidence of mouth hooking in other fisheries (see the review by Cooke and Suski, 2004), may not offer an appreciable conservation benefit for black sea bass, given the already low incidence of deep hooking observed with the high-low tackle rig and octopus hooks used in this study.

The survivorship assessment used to infer fate of individual fish was complex but warranted, given the variable acoustic detection histories evident for black sea bass of both known (i.e., positive and negative controls) and unknown fate. In previous studies, animal fate has been successfully reconciled by using solely the depth-variance test (e.g., for Atlantic cod; Capizzano et al., 2016) we employed in our study. However, when applied to our detection data, neither of these quantitative techniques was able to consistently predict the fate of all black sea bass (i.e., analyses with these techniques predicted different fates for nearly half of the detected fish), an outcome that was similar to that of previous work with haddock (Melanogrammus aeglefinus) in the Gulf of Maine (Capizzano et al., 2019). Because of this discrepancy, it was necessary to take a semiquantitative approach that both visually compared fish horizontal and vertical movements to those of positive and negative controls and predicted bottom currents in the study area to satisfactorily determine the fate of a large number of individuals. Although this approach lacked the full quantitative rigor of the depth-variance test, it was particularly effective at identifying predation events and at predicting the fate of fish with very short (i.e., hours) detection histories. Our methods can serve as a useful model for future studies, given that the analytical approaches for determining the fate of animals tagged with acoustic transmitters, as a part of discard mortality studies, frequently need to be developed specifically for a study and its unique factors, such as array design and animal behavior. 
The successful identification of factors that influenced mortality, and therefore the discard mortality rate, of black sea bass in the winter offshore recreational fishery off New Jersey permitted formulation of recommendations for best practices in catch-and-release procedures aimed at reducing discard mortality. On the basis of the findings that swim bladder venting (when done correctly) was the most influential factor affecting discard mortality and that it increased submergence success over all depths (i.e., reduced the incidence of floating), we recommend that anglers vent all black sea bass before releasing them during the winter offshore fishery season. Given the finding that longer fight times (>54 s) increased mortality in the subsample of fish tagged with acoustic transmitters, another logical step is to explore methods to minimize the time black sea bass spend on the line while being reeled up to the surface.

Results of analysis with the generalized additive mixedeffect model indicate that capture depth had the largest influence on fight time; therefore, we recommend that anglers target black sea bass in water that is as shallow as possible. Although lower speed reels yielded longer fight times on average, the effect of individual angler had a seemingly large effect on the apparent relationship. In other words, angler behavior seemed to influence the effect that reel gear had on fight time more than the reel gear ratio itself. Given this finding, it is more logical (and practical) to recommend that anglers reel their catch to the surface at a moderate to fast pace, rather than to implement restrictions on reel gear. Capture as a part of a double header also resulted in increased fight time. Therefore, discard mortality may be reduced if anglers limit the number of hooks on their rigs. Also, we recommend that anglers use fishing gear (i.e., rod and reel or line) of appropriate strength for the area in which they fish to avoid unnecessary increases in fight time and discard mortality.

\section{Acknowledgments}

Thank you to the industry partners and volunteers who assisted with fieldwork and reporting recaptures. Thanks to J. Kohut, H. Roarty, and C. Liu for helping to acquire oceanographic data. H. Benoît assisted with the survival analysis, and multiple researchers provided acoustic detections data through the Atlantic Cooperative Telemetry Network (D. Haulsee, University of Delaware; E. Rothermel, University of Maryland; and E. Ingram, Stony Brook University). This research was funded by the Mid-Atlantic Fishery Management Council's Collaborative Research Program.

\section{Literature cited}

Allen, S. E., M. S. Dinniman, J. M. Klinck, D. D. Gorby, A. J. Hewett, and B. M. Hickey.

2003. On vertical advection truncation errors in terrainfollowing numerical models: comparison to a laboratory model for upwelling over submarine canyons. J. Geophys. Res. 108:3-1-3-36. Crossref

Benoît, H. P., T. Hurlbut, and J. Chassé.

2010. Assessing the factors influencing discard mortality of demersal fishes using a semi-quantitative indicator of survival potential. Fish. Res. 106:436-447. Crossref

Benoît, H. P., T. Hurlbut, J. Chassé, and I. D. Jonsen.

2012. Estimating fishery-scale rates of discard mortality using conditional reasoning. Fish. Res. 125-126:318-330. Crossref

Benoît, H. P., C. W. Capizzano, R. J. Knotek, D. B. Rudders, J. A. Sulikowski, M. J. Dean, W. Hoffman, D. R. Zemeckis, and

J. W. Mandelman.

2015. A generalized model for longitudinal short- and longterm mortality data for commercial fishery discards and recreational fishery catch-and-releases. ICES J. Mar. Sci. 72:1834-1847. Crossref

Brownscombe, J. W., A. J. Danylchuk, J. M. Chapman, L. F. G. Gutowsky, and S. J. Cooke.

2017. Best practices for catch-and-release recreational fisheries—angling tools and tactics. Fish. Res. 186:693-705. Crossref

Bugley, K., and G. Shepherd.

1991. Management briefs: effects of catch-and-release angling on the survival of black sea bass. North Am. J. Fish. Manage. 11:468-471. Crossref

Burnham, K. P., and D. R. Anderson.

2002. Model selection and multimodel inference: a practical information-theoretic approach, 2nd ed., 488 p. SpringerVerlag New York Inc., New York.

Capizzano, C. W., J. W. Mandelman, W. S. Hoffman, M. J. Dean, D. R. Zemeckis, H. P. Benoît, J. Kneebone, E. Jones, M. J. Stettner, N. J. Buchan, et al.

2016. Estimating and mitigating the discard mortality of Atlantic cod (Gadus morhua) in the Gulf of Maine recreational rod-and-reel fishery. ICES J. Mar. Sci. 73:23422355. Crossref

Capizzano, C. W., D. R. Zemeckis, W. S. Hoffman, H. P. Benoît, E. Jones, M. J. Dean, N. Ribblett, J. A. Sulikowski, and J. W. Mandelman.

2019. Fishery-scale discard mortality rate estimate for haddock in the Gulf of Maine recreational fishery. North Am. J. Fish. Manage. 39:964-979. Crossref

Collins, M. R., J. C. McGovern, G. R. Sedberry, H. S. Meister, and R. Pardieck.

1999. Swim bladder deflation in black sea bass and vermilion snapper: potential for increasing postrelease survival. North Am. J. Fish. Manage. 19:828-832. Crossref

Cooke, S. J., and C. D. Suski.

2004. Are circle hooks an effective tool for conserving marine and freshwater recreational catch-and-release fisheries? Aquat. Conserv. 14:299-326. Crossref

Cox, D. R.

1972. Regression models and life-tables. J. R. Stat. Soc., B 34:187-220.

Cox, D. R., and D. Oakes.

1984. Analysis of survival data, 212 p. Chapman and Hall Ltd., London.

Crandall, C. A., T. M. Garlock, and K. Lorenzen.

2018. Understanding resource-conserving behaviors among fishers: barotrauma mitigation and the power of subjective norms in Florida's reef fisheries. North Am. J. Fish. Manage. 38:271-280. Crossref

Curtis, J. M., M. W. Johnson, S. L. Diamond, and G. W. Stunz.

2015. Quantifying delayed mortality from barotrauma impairment in discarded red snapper using acoustic telemetry. Mar. Coast. Fish. 7:434-449. Crossref 
Davis, M. W.

2002. Key principles for understanding fish bycatch discard mortality. Can. J. Fish. Aquat. Sci. 59:1834-1843. Crossref

Drumhiller, K. L., M. W. Johnson, S. L. Diamond, M. M. R. Robillard, and G. W. Stunz.

2014. Venting or rapid recompression increase survival and improve recovery of red snapper with barotrauma. Mar. Coast. Fish. 6:190-199. Crossref

Eberts, R. L., and C. M. Somers.

2017. Venting and descending devices provide equivocal benefits for catch-and-release survival: study design influences the effectiveness more than barotrauma relief method. North Am. J. Fish. Manage. 37:612-623. Crossref

Eberts, R. L., M. A. Zak, R. G. Manzon, and C. M. Somers.

2018. Walleye responses to barotrauma relief treatments for catch-and-release angling: short-term changes to condition and behavior. J. Fish. Wildl. Manage. 9:415-430. Crossref

Hannah, R. W., P. S. Rankin, and M. T. O. Blume.

2014. The divergent effect of capture depth and associated post-recompression survival of canary (Sebsates pinniger) and yelloweye rockfish (S. ruberrimus). Fish. Res. 157:106-112. Crossref

Harrington, D. P., and T. R. Fleming.

1982. A class of rank test procedures for censored survival data. Biometrika 69:553-566. Crossref

Jarvis, E. T., and C. G. Lowe.

2008. The effects of barotrauma on the catch-and-release survival of southern California nearshore and shelf rockfish (Scorpaenidae, Sebastes spp.). Can. J. Fish. Aquat. Sci. 65:1286-1296. Crossref

Kelley, D., and C. Richards.

2017. oce: analysis of oceanographic data. $\mathrm{R}$ package, vers. 0.9-21. [Available from website, accessed February 2018.]

Knotek, R. J., D. B. Rudders, J. W. Mandelman, H. P. Benoît, and J. A. Sulikowski.

2018. The survival of rajids discarded in the New England scallop dredge fisheries. Fish. Res. 198:50-62. Crossref

Lee, M.-Y., S. Steinback, and K. Wallmo.

2017. Applying a bioeconomic model to recreational fisheries management: groundfish in the northeast United States. Mar. Resour. Econ. 32:191-216. Crossref

Moser, J., and G. R. Shepherd.

2009. Seasonal distribution and movement of black sea bass (Centropristis striata) in the northwest Atlantic as determined from a mark-recapture experiment. J. Northw. Atl. Fish. Sci. 40:17-28. Crossref

NMFS (National Marine Fisheries Service).

2018. Fisheries economics of the United States, 2016. NOAA Tech. Memo. NMFS-F/SPO-187, 243 p.

Ott, R. L., and M. Longnecker.

2010. An introduction to statistical methods and data analysis, 6th ed., 1273 p. Brooks/Cole, Cengage Learning, Belmont, CA.

Pulver, J. R.

2017. Sink or swim? Factors affecting immediate discard mortality for the Gulf of Mexico commercial reef fish fishery. Fish. Res. 188:166-172. Crossref

NEFSC (Northeast Fisheries Science Center).

2017. 62nd Northeast regional stock assessment workshop (62nd SAW) assessment report. Northeast Fish. Sci. Cent. Ref. Doc. 17-03, 822 p. [Available from website.]
R Core Team.

2018. R: a language and environment for statistical computing. R Foundation for Statistical Computing, Vienna, Austria. [Available from website, accessed February 2018.] ROMS/TOMS Group.

2013. ROMS: Regional Ocean Modeling System. The ROMS/ TOMS Group. [Available from website.]

Rudershausen, P. J., J. A. Buckel, and J. E. Hightower.

2014. Estimating reef fish discard mortality using surface and bottom tagging: effects of hook injury and barotrauma. Can. J. Fish. Aquat. Sci. 71:514-520. Crossref

Runde, B. J., and J. A. Buckel.

2018. Descender devices are promising tools for increasing survival in deepwater groupers. Mar. Coast. Fish. 10:100-117. Crossref

Sauls, B.

2014. Relative survival of gags Mycteroperca microlepis released within a recreational hook-and-line fishery: application of the Cox regression model to control for heterogeneity in a large-scale mark-recapture study. Fish. Res. 150:18-27. Crossref

Scyphers, S. B., F. J. Fodrie, F. J. Hernandez Jr., S. P. Powers, and R. L. Shipp.

2013. Venting and reef fish survival: perceptions and participation rates among recreational anglers in the northern Gulf of Mexico. North Am. J. Fish. Manage. 33:1071-1078. Crossref

Stephen, J. A., and P. J. Harris.

2010. Commercial catch composition wit discard and immediate release mortality proportions off the southeastern coast of the United States. Fish. Res. 103:18-24. Crossref

Therneau, T. M., and P. M. Grambsch.

2000. Modeling survival data: extending the Cox model, $350 \mathrm{p}$. Springer-Verlag New York Inc., New York.

Venables, W. N., and B. D. Ripley.

2002. MASS: modern applied statistics with S, 4th ed., $495 \mathrm{p}$. Springer, New York.

Weltersbach, M. S., W.-C. Lewin, J. P. Gröger, and H. V. Strehlow. 2019. Effect of lure and bait type on catch, size, hooking location, injury and bycatch in the western Baltic Sea recreational cod fishery. Fish. Res. 210:121-130. Crossref

White, J. W., and B. I. Ruttenberg.

2007. Discriminant function analysis in marine ecology: some oversights and their solutions. Mar. Ecol. Prog. Ser. 329:301-305. Crossref

Wilde, G. R.

2009. Does venting promote survival of released fish? Fisheries 34:20-28. Crossref

Winton, M. V., J. Kneebone, D. R. Zemeckis, and G. Fay.

2018. A spatial point process model to estimate individual centers of activity from passive acoustic telemetry data. Methods Ecol. Evol. 9:2262-2272. Crossref

Wood, S. N.

2011. Fast stable restricted maximum likelihood and marginal likelihood estimation of semiparametric generalized linear models. J. R. Stat. Soc., B 73:3-36. Crossref

Yergey, M. E., T. M. Grothues, K. W. Able, C. Crawford, and K. DeCristofer.

2012. Evaluating discard mortality of summer flounder (Paralichthys dentatus) in the commercial trawl fishery: developing acoustic telemetry techniques. Fish. Res. 115116:72-81. Crossref 